\title{
Pulling It Together: Human Resilience and Community in Toni
}

\section{Morrison's Beloved}

\author{
Ankur Yadav \\ PhD Research Scholar \\ Department of English \\ Dr Bhimrao Ambedkar University \\ Agra, Uttar Pradesh, India \\ ankur.bpsetah@gmail.com
}

\begin{abstract}
Toni Morrison's Beloved is the story of the sufferings of Afro-American's slavery, trauma of being forced to leave their homelands, horrors of parting with their relatives and the resilience of the Black Community to restore peace and harmony among themselves. The present paper demonstrates the extent to which individuals need the support of their communities in order to survive and how the community as a whole rises resiliently to overcome the trauma and pacify the sufferings of individuals. Morrison in this novel, benevolently asserts the need of community, its solidarity and its interdependence in offering resistance and kindling the spirit of resilience for the individual redemption by knitting a diverse and fragmented narrative only to be exorcised for a better future.
\end{abstract}

Keywords: Black Community, Human Resilience, Resistance, Trauma, Solidarity.

Beloved is a story no one wants to remember and still no one can forget. It is a story of abysmal atrocities and kindled hopes. It is a story of inflicting pain and tender healing. It is a story of individual separation and community solidarity. It is a story of institutional oppression and resilience of the community. Beloved is a poignant novel because of the injustice and 
oppression it incorporates. However, the resilience of the human spirit transcends the text and triumphs through the powerful rendering of characters and solidarity of the community alike.

Beloved entices the critical appreciation of the text because of the constant tussle between survival and suffering, horror and hope. Morrison, in this novel, has expanded the horizons of a slave narrative by exploring the profound damages caused to the slaves and the promise of resilience and healing through the endurance and togetherness of Sethe, her loved ones and the community. The novel traces the journey of Sethe and Paul D, who are born in slavery, but escape the clutches of slavery eventually through their determination and channels of aid and fostering by various people on their path to redemption. The present paper attempts to accentuate the interdependency of the characters and the community and how the community works together in the times of crisis. The paper categorically manifests how community, in the novel, functions in solidarity, the interdependence of fragmented characters who exist in duality with the community, how the narrative of the text operates on dual planes of literal significance and structural unison, and how naming culture in the text echoes the solidarity and camaraderie.

Unlike the most slave narratives that predominantly trace the journey of a solitary male character, Beloved exhibits how Paul D needs the aid of other people to escape his bondage. Morrison intrinsically chronicles the journey of Paul D in the novel. The minor characters assist him in his journey which culminates with Sethe. The slaves at Sweet Home devise a plan to escape but even after most of them being unsuccessful in their enterprise, they allow others to escape. In Georgia too, Paul D is able to escape with the help of his fellow prisoners. After escaping from the prison, it is Cherokee who instructs Paul D to follow the flowering tress to the north. These instructions play a vital role in finding Cincinnati. Additionally, in Delaware, Paul D is fostered by a weaver lady who provides him food and shelter. 
Sethe, too, has been leading a turbulent life for the past eighteen years. Like Paul D, she also receives help along her way to freedom. Surprisingly, only Sethe and her children manage to escape the Sweet Home bondage. In the novel, Sethe is healed and cured thrice: first by Amy Denver, second by her mother-in-law Baby Suggs and finally by Paul D. Amy Denver, who is also on a runaway from her malicious owner, assists a pregnant Sethe and heals her wounds. Amy also makes an astonishingly insightful statement that foreshadows the novel's events. While massaging Sethe's feet, she says "Anything dead coming back to life, hurts". Indeed, the return of Beloved from death hurts everyone involved. Amy states, "can't nothing heal without pain" presaging the pain Sethe will inflict upon before forgiving herself. The statement also echoes the trauma of slavery. Later, on her journey to Cincinnati, Sethe meets ex-slaves: Ella, John and Stamp Paid who also assist her along her way. Stamp Paid helps her cross the Ohio river, while Ella and John provide food and clothes to Sethe thus aiding her to reach 124. Paul D and Sethe both realize that they need each other to fix their missing parts of life and complete their 'whole'. Infact in one of the intimate moments of the novel, Paul D says to Sethe:

"I'm a walking man, but I been heading in this direction for seven years. Walking all around this place. Upstate, downstate, east, west; I been in territory ain't got no name, never staying nowhere long. But when I got here and sat out there on the porch, waiting for you, well, I knew it wasn't the place I was heading toward; it was you. We can make a life, girl. A life." (Morrison 46) Sethe too begins to reassemble herself emotionally when Paul D washes her in sections. These episodes of tender caring and nurturing exemplify the prominence of communal integrity and solidarity. While the undaunting courage of Paul D and stoic facade of Sethe seem heroic, they are far from being pragmatic.

Throughout Beloved, Morrison asserts the power of community and manifests how solidarity in community functions as resistance and resilience amidst the crisis. The Sweet 
Home slaves forge a small community in the obnoxious farms. But this community is neither automatic nor regulated, it is rather an agency of care, compassion, and confrontation. Instead of forcing their will, this community allows Sethe to choose a husband for her and abide by her decision without any contempt. Similarly, this community concocts the plan of escaping together but allows one another to decide whether they will participate in the plan or not. The solidarity of this community triumphs when the Schoolteacher, even after capturing most of the slaves, fails in his inquiry to know about their plan.

Though, the discourse of slavery values autonomy and freedom because of the lucid manifestation of most of them being un-free. Morrison endeavours to deconstruct this valuation of autonomy as it is laid on the grounds of oppression, injustice and enslavement. She problematizes the valuation of autonomy and does not idealize the power of community without any restraint. She asserts that a community devoid of regard for its individual is as menacing as an individual who does not adhere to the integrity of the community in which he or she lives. The most heart-rending example of this is when the Cincinnati community succumbs to treachery by intentionally failing to inform Sethe about the Schoolteacher's approaching. The community which is meant for protecting, abysmally shuns her and pushes her to the boundary where the line between good and bad, blurs. In order to save her daughter from the trauma of slavery, Sethe stoically kills her. Stamp Paid is mindful of the grief this incident forced on Baby Suggs: "to belong to a community of other free Negroes-to love and be loved by them, to counsel and be counselled, protect and be protected, feed and be fed-and then to have that community step back and hold itself at a distance-well, it could wear out even a Baby Suggs, holy.” (Morrison 177)

Baby Suggs believed in the power of community. However, her principles and values of community annihilate after being shunned by the community she loved, cared, respected and protected. By accentuating community's jealousy and betrayal after the feast, Morrison 
demonstrates that the community, by acting against an individual, confers a social order prompting the murder of Beloved. In the end, the community subverts this order by first assisting Denver with the food and support she requires for her destitute family and redeeming itself by abandoning Sethe to commit another heinous crime.

Paul D is able to break free from the prison in Georgia because of the bond that strengthened between the slaves. He manages to escape courtesy, the literal symbol of chain. In Sweet Home, the slaves also plan to run off. However, they are separated. In the Georgia Prison, the equation of separation rules out as the slaves are chained. These slaves are not only chained literally but symbolically too. Morrison has used the symbol of chain metaphorically in the novel. The chain not only binds the slaves together but also facilitates as a spiritual and emotional linkage for the slaves. The chain links the slaves together and forms a bond which lets them guide each other in the muddy flood waters during the rainstorm and runaway together.

“One lost, all lost. The chain that held them will save all or none”(Morrison 110).

Morrison aesthetically metamorphoses the chain from an epitome of oppression and tyranny to a symbol of solidarity and resilience. The chain was intended to keep the prisoners tied but becomes instrumental in the slaves' triumph. The chain does not allow any of the prisoners to be lost or drowned. Morrison posits how the hegemonic order like thechained men can be subverted. It is this subversion of the chain that embellish community as the prominent agency of resilience in the novel. By subverting the hegemonic order of chain, Morrison undermines the images of slavery by reinventing, reinforcing and rewriting the narrative to exhibit hope and strength through communal solidarity.

In Beloved, the naming culture evolves from the discourse of slavery and the agency of resilience. It is a key aspect in manifesting the community solidarity and asserting autonomy. Names are given to distinguish among the individuals. However, the name Paul A, Paul, D and 
Paul F seem similar echoing the commodification and enslavement. Names are objected with the process of identification but ironically, here the slaves do not even possess an identity of their own but a borrowed one given by their masters. What is more horrific is the missing letters.The absence of letters signifies human loss in the novel. Six-O also exemplifies this sequence and refers to his unborn progeny as Seven-O. Paradoxically, sequential naming enables the slaves to identify each other and forge a bond among themselves. Although these names symbolize a paradigm of commodification and domination, other names in Beloved such as Halle, Stamp Paid, Denver, Baby Suggs and Sethe embody resistance and resilience to decimate slavery.

Baby Suggs renames herself after her husband's last name. She names her child on her own. She doesn't keep the name 'Jenny' that her masters labeled her, thus, denying the authoritarian paradigms and resonating a spirit of resistance and resilience. The name 'Beloved' not only proclaims the love of Sethe for her daughter but also the resilience towards these paradigms of commodification and enslavement. In a world where slaves are not even entitled to confer a name of their choice; to name her daughter 'Beloved' is a sense of reclamation, resistance and resilience.

Beloved is a narrative of seemingly intertwined stories of diverse people. These stories within Beloved create a community which solidifies the spirit of resilience among its individuals. The narrative of the text functions on a dual plane. Firstly, the story attributes to its sense of reclamation and resilience through its diverse characters and their stories. Secondly, these fragmented pluralities of the narratives intertwine structurally to contribute to a master narrative which asserts the dominance and necessity of solidarity. Archetypal of this nature is the unison of three fragmented monologues by Denver, Sethe and Beloved. After giving insights about their respective minds, their voices mingle and it becomes increasingly difficult to attribute the phrases to its appropriate speaker: 


\section{"Beloved}

You are my sister

You are my daughter

You are my face; you are me"'(Morrison 216)

The primary interpretation of this predicament is the formulation of a coherent identity of Sethe, Denver and Beloved which is beyond recognition. This coherent identity does not only echo the filial issues which enforce the main narrative but also on a parallel plane, is an epitome of confounding issues pertaining to the slave society.

Paul D and Sethe's pasts are the epitome of tyranny and oppression. They have incurred recurring loses, yet their future awaits a love story. Infact, their union does not symbolize the merging of stories but echoes the companion pieces linked together. While knitting the stories of Paul D and Sethe, Morrison simultaneously concocts the stories of Sweet Home slaves, Amy Denver, the Cherokee tribespeople, Ella, John and Stamp Paid. The narrative of Beloved is like a jigsaw puzzle that requires the assembly of fragmented narratives to formulate a complete picture. The result is an assertion positing that the subjectivity of an individual can only be formed within the relative context of the community, whereas the community's solidarity hinges upon the individual identities and strength of each of its members.

Beloved is an emotionally excruciating novel to read. Like its titular character, the novel as an entity, is perplexing - one that can distress or inspire the reader with equal amount of potency. Yet, by confronting this disturbing and unrelenting force in a diligent way, one can comprehend the past to learn about the spirit of human resilience to inspire our present and illuminate our future contours. The book as a whole gives voices to the suppressed history. It recovers memories through diverse fragmented narratives only to be exorcised for a better future. Morrison in this novel, benevolently asserts the need of community, its solidarity and its interdependence in offering resistance and kindling the spirit of resilience for the individual 
redemption. The solidarity of community in Beloved recuperates the community by pulling itself together that would otherwise be lost to ravages of willed silence and further succumb the oppressed community. 


\section{References}

Morrison, Toni. Beloved. Vintage Books, 2004.

Bloom, Harold. Toni Morisson's Beloved: Modern Critical Interpretations. Bloom's Literary Criticism, 2009.

Tally, J. The Cambridge Companion to Toni Morrison. Cambridge, 2007. 